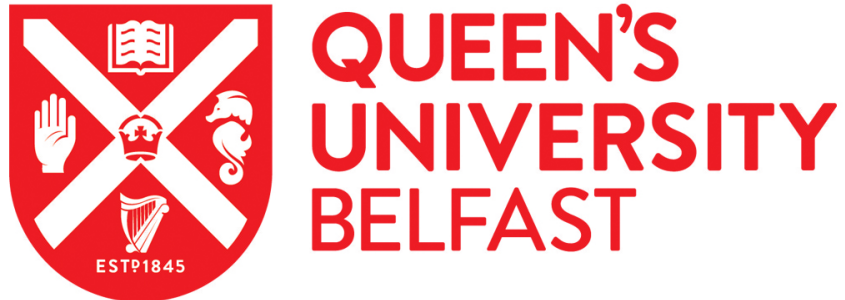

\section{Reviewing the Literature on the Breakdown of Foster Care Placements for Young People: Complexity and the Social Work Task}

Harkin, C., \& Houston, S. (2016). Reviewing the Literature on the Breakdown of Foster Care Placements for Young People: Complexity and the Social Work Task. Child Care in Practice, 22(2), 98-112. https://doi.org/10.1080/13575279.2015.1102124

Published in:

Child Care in Practice

Document Version:

Peer reviewed version

Queen's University Belfast - Research Portal:

Link to publication record in Queen's University Belfast Research Portal

Publisher rights

Copyright 2016 Taylor \& Francis.

This work is made available online in accordance with the publisher's policies. Please refer to any applicable terms of use of the publisher.

\section{General rights}

Copyright for the publications made accessible via the Queen's University Belfast Research Portal is retained by the author(s) and / or other copyright owners and it is a condition of accessing these publications that users recognise and abide by the legal requirements associated with these rights.

Take down policy

The Research Portal is Queen's institutional repository that provides access to Queen's research output. Every effort has been made to ensure that content in the Research Portal does not infringe any person's rights, or applicable UK laws. If you discover content in the Research Portal that you believe breaches copyright or violates any law, please contact openaccess@qub.ac.uk. 


\section{Reviewing the Literature on the Breakdown of Foster Care Placements for Young People: Complexity and the Social Work Task}

Young people in long-term foster care are at risk of experiencing poor social, emotional, behavioural and educational outcomes. Moreover, these placements have a significantly greater chance of breaking down compared to those involving children. This article critically evaluates the factors associated with this particular outcome. It was carried out through a literature review conducted by a social work practitioner in one Health and Social Care Trust in Northern Ireland. The findings evidenced that, apart from overriding safety concerns, placement breakdown was not a one-off event but rather a complex process involving the interplay between a range of dynamic risk and protective factors over time, operating in the wider context of the young person's history and life experiences. The significance of these findings for social work practitioners is finally considered by identifying key theories to inform understanding and intervention.

Key words: adolescence, fostering breakdown, social work

\section{Introduction}

Young people in long-term foster care are at risk of succumbing to poor social, emotional, behavioural and educational outcomes based on their pre-care experiences and the impact of the care system itself (Jones Harden, 2004; Fernandez, 2008; Leve et al., 2012). Moreover, anecdotal reports within the lead author's Health and Social Care Trust, have registered an increased frequency of placement breakdown, with young people often resident in these placements since early childhood and difficulties only emerging in the teenage years. In this context, foster carers invariably state that they can no longer sustain the placement. To compound matters, the limited availability of alternative placements often results in young people being placed in supported housing schemes, or what is termed unregulated placements. Therefore, from a starting point of disadvantage and vulnerability, these young people have been forced to undertake their journey to adulthood at an 'accelerated and compressed' rate with a limited support network in comparison to most of their peers in the general population (Stein, 2008:39). 
This particular career pattern provided a strong rationale for carrying out a structured review of the literature in order to heighten knowledge and improve outcomes. A further motivation came from the first Strategy for Social Work in Northern Ireland (DHSSPS, 2012:6). It advised that 'social work practice must be based on evidence of what works'. Taking this directive on board, this literature review sought to evaluate some of the factors associated with the breakdown of long-term foster care placements during adolescence, and to explore the needs of these looked-after young people and their foster carers. Furthermore, it aimed to raise salient issues for frontline practitioners, particularly as regards understanding and intervening in complex situations.

\section{Method}

To commence the review, key concepts were defined, search terms elicited and parameters identified.

\section{Definitions}

\section{Age Categories}

This review mostly focused on the age band, $13-18$ years. The term 'young person' was used to categorise this interval. Where participants in the age range below it were also included in a study's sample, we have referred to them as 'children'.

\section{Foster care}

Foster care can vary in type, purpose and duration. This review adopted the Western Health and Social Care Trust's (2012: 5) definition of long-term care, viewing it as an 'alternative provided to young people who cannot live with their own parents, where they can benefit from a loving safe and stable home for as long as they need it'.

\section{Foster care placement breakdown}

Various terms have described the ending of long-term foster care placements in an unexpected manner, including 'breakdown' and 'disruption'. Berridge and Cleaver's (1987: 6) definition was adopted within the review. They construed breakdown as 'an 
unanticipated and untimely placement ending that is not included in the young person's care plan'.

\section{Search strategy}

Both the online university resources and those of Health On the Net Northern Ireland (HONNI) were utilised to conduct a comprehensive search. Search strategies were carried out via host databases notably, EBSCO and OvidSP. Other databases accessed included Psychinfo, SocIndex, Social Care online, Scopus, Google Scholar and IBSS. In addition, key texts were accessed including relevant books, 'grey' material, and journals (for example, Fostering and Adoption, the British Journal of Social Work, Child Care in Practice, Qualitative Social Work and Child Abuse and Neglect). Internet searches of key health and social care websites added to the corpus (such as the website of Department of Health, Social Services and Public Safety). Finally, the reference lists of key texts and journal articles were scanned and further sources identified.

\section{Search parameters}

Although each database required uniquely adapted search strategies in order to obtain the optimum number of results, the core search parameters remained the same. To ensure the literature was relatively up-to-date, the search was (mostly) confined to the last ten year period. Given practical constraints, only English language sources were targeted. As the review sought to develop learning in respect of working with looked-after young people, and foster carers within the context of a westernised welfare model, the search strategy extended to literature from other Anglophone countries, such as Australia and the United States. In terms of a purported hierarchy of research evidence, a decision was made not to automatically exclude any material based on the study's design alone. This decision reflected the diverse and generally qualitative nature of the data within this area.

\section{Search terms}

An initial review of the literature highlighted the range of contrasting terms used in different countries for the areas under consideration. For example, 'placement breakdown' has been referred to as 'disruption', 'instability' and 'unplanned ending'. The number of references, using the range of different terms, however, were very limited. Using broader terms, 
including 'looked-after', 'state care', 'foster-care', 'placement' and 'outcome', generated a much greater number of sources. Adopting Boolean operators (AND, OR and NOT) and truncation (such as foster car*) elicited a more focused and relevant range. Yet, as the number still remained high, a manual check was then undertaken with regard to the primary relevance of the source for social work practice along with its adherence to the quality measures outlined below (see 'Critical Appraisal').

\section{Critical appraisal}

Seeking to establish a consistent measure of quality, the Social Care Institute for Excellence's principles of transparency, accuracy, purposivity, utility, propriety, accessibility and specificity (Pawson et al., 2003) underpinned the critical analysis of the research studies in this review. Furthermore, the evaluative questions contained within the Centre for Evidence-Based Social Services' Critical Thinking tool for qualitative research, also helped inform judgements. This tool included a focus on the trustworthiness of data collection and analysis, ethical issues and relevance to practice (Newman et al., 2005).

\section{Key themes from the review}

A number of key themes emerged from the review of the literature on fostering breakdown, namely: (i) factors related to the young person; (ii) factors related to the foster carers; (iii) the role of the birth family and contact; and (iv) the role of social workers.

\section{Factors related to the young person}

Young people's externalising or anti-social behaviours were frequently identified as factors associated with placement breakdown. This was a prominent finding in Oosterman et al.'s (2007) meta-analysis on the topic. In another study of 68 young people in foster care in the UK, Farmer et al. (2004) assessed the impact of young person-related factors on placement outcomes. They also analysed the parenting task for foster carers and how their role contributed to these outcomes. They found that young people's behavioural difficulties significantly influenced placement breakdown and, those entering a placement at an older age, or directly from living at home, were at a greater risk of this outcome. Farmer et al.'s findings were echoed in Oosterman et al.'s study (2007) but placed the young person's 
behaviour in a broader context pointing to a more complex understanding of the nature of the disruption.

In contrast to these findings, a longitudinal study (Egelund and Vitus, 2009) investigating the breakdown of placements within a sample of 227 young people in Denmark, did not identify anti-social behaviour as a key factor relating to placement breakdown. Rather, emotional difficulties experienced by the young people were reported as predictive of this outcome. However, the young people in the sample were predominately residing in residential care or in 'socio-pedagogical homes' (small units dealing with specific client groups), with a small number in foster care. Working with young people with behavioural difficulties was part of the remit of these types of care placement, thus becoming an ostensible factor ameliorating rates of breakdown.

Sallnas et al's research (2004) echoed the afore-mentioned themes. They sought to understand the reasons behind the premature ending of placements in their study of a representative, national sample of 776 young people in Sweden placed in out-of-home care in 1991. Extracting data from state case files, they discovered that non-kinship foster care placements experienced the highest rate of breakdown, and that young people experiencing mental health issues and demonstrating anti-social behaviours, were found to be most at risk of this event occurring. Despite the study's large sample size, however, it was drawn from a population already experiencing behavioural issues, making it hard to determine how much of the presenting anti-social behaviours were linked to the experience of care itself.

In a related vein, Sinclair et al. (2005) analysed a cross-sectional sample of 472 children and young people in foster care in 7 UK local authorities. They sought to identify risk and protective factors in foster care placements, and the support required by foster carers. Data were derived from questionnaires sent to the cohort's foster carers, field and family placement social workers. This process was repeated 14 months later with the addition of questionnaires sent to children and young poeple aged 5 and over. Views were sought from a range of key stakeholders enhancing the validity of the findings through triangulation. Sinclair et al. asserted that there were a number of child and young person factors related to placement breakdown: older age, difficult behaviours inside and outside the home (emanating from peer associations), attachment difficulties, the child or young person 
wanting to leave the placement, or not being perceived as having redeeming features by the foster carers. These findings presented a young person's behaviour in a broader context of their age, previous life history and relationship with carers.

Interestingly, Sinclair et al. (2005) reported emotional abuse as more predictive of negative outcomes that other types of abuse. By way of comparison, Farmer et al (2004) did not detect any difference in placement outcome according to the young person's past experience of neglect, physical or sexual abuse, though the role of emotional abuse was not considered explicitly. That said, it was recognised that some level of emotional abuse was involved in most if not all types of mal-treatment (DHSSPSNI, 2005). In this context, difficult externalising behaviours and internalising behaviours, such as depression and anxiety, have been viewed as part of a broad spectrum of indicators suggesting some level of emotional distress for young people (Stanley et al., 2005; Simmonds, 2010).

Staying with the theme of emotional distress, a greater prevalence of mental health disorder had been detected among looked-after young people compared with those in the general population (Stanley et al., 2005; Scott and Hill, 2006). Meltzer et al.'s (2003) seminal study, sampling 1039 looked-after children and young people aged 5-17, from 134 English Local Authorities, reported that $45 \%$ of this population in the UK had a diagnosable mental health disorder. These high rates of mental health concern have been attributed to the complex interplay between the young person's experience of adversity prior to entering care, and the care experience itself (Stanley, 2005; Fernandez, 2008).

Adding flesh to these findings, attachment theory (Bowlby, 1969) promotes understanding of how young people can be shaped by early life experiences of poor caregiving, neglect and abuse developing insecure attachments, lacking trust in a caregiver's response, and having internal working models characterised by feelings of being unworthy and unloved (Hek et al, 2010). It is known that insecure attachments can affect behaviour, emotional regulation, and an ability to form new attachments with foster carers (Farmer et al., 2004; Sinclair et al, 2005). Some commentators, however, have contested the predictive capacity of attachment theory, asserting the young person's ability to adapt within positive environments and the importance of assessing any behavioural issues within the context of the current situation (Barth et al., 2005). 
Pursuing this central theme of emotions and social behaviours, Stanley et al. (2005) examined the mental health needs of looked-after children, and the service response to them, in two local authorities in the North of England. This was undertaken through a purposive sample of 80 looked-after children and young people, aged 5-16, in residential and foster care. Whilst acknowledging a selection bias towards those of highest need, the researchers found that displays of anger, aggression and low self-esteem were most prevalent in the population. Moreover, they discovered a positive association between high numbers of previous placements and the greatest levels of mental health disturbance, yet noted that it was unclear whether mental health distress was a result of placement breakdown or a contributory factor to it (or both).

Linked to these observations was Rich's (1996) contention that foster care placement breakdown could undermine a young person's self-concept, heightening attachment behaviours, emotional regulation and behavioural difficulties, as part of a self-perpetuating cycle undermining the stability of future placements. This view was reaffirmed by Brown and Bednar's (2006: 1498) conclusion that the effect of placement breakdown 'could intensify and contribute to greater challenges in each subsequent placement'.

It is worth noting at this point that adolescence can be a time of uncertainty and transition for all young people as they confront physical, psychological and emotional changes while seeking to develop their own adult identity (Fahlberg, 1995; Crawford and Walker, 2007). For looked-after young people with existing traumas, stressful transitions can reawaken maladaptive strategies learned in childhood provoking withdrawn, avoidant or aggressive reactions (Schofield and Beek, 2009). Yet, some young people demonstrate a greater resilience with which to overcome adversity, drawn from factors within themselves, their wider family and community, such as the secure base provided by foster carers, protecting them against risk and promoting positive life outcomes (Daniel and Wassell, 2002; Atwool, 2006; Cashmore and Paxman, 2006; Canavan, 2008; Gilligan, 2008).

Despite this high prevalence of emotional and psychological need within the young people, it was clear that they received limited help from mental health services (James, 2004). Significantly, when appropriate therapeutic support was provided, the likelihood of placement breakdown lowered (Farmer et al., 2004). This was the case even though the 
factors leading to placement breakdown also appeared to hamper young people's capacity to avail of therapeutic help (Stanley et al., 2005; Scott and Hill, 2006). Given what has been said, timely and uncomplicated access to therapeutic support was vital for well-being and placement stability (Stanley et al., 2005). For the majority of young people and their foster carers, though, help came mainly from frontline social work staff rather than clinical practitioners (Stanley et al., 2005). Evidently, these staff were required to work with increasingly risky and complex situations due to difficulties accessing specialist CAHMS support (DHSSPS, 2006).

Interestingly, Simmonds (2010: 609) identified foster carers as 'the immediate primary therapeutic agents' for young people, highlighting how the use of relationship as a medium was central to meeting the young person's emotional needs and thus heightening placement stability. Simmonds also stressed the value of foster carers adapting their parenting approach to the emotional and behavioural survival strategies displayed by young people. That said, foster carers have referred to the limitations in training and support to deal with complex mental health issues, particularly at times of crisis (Buehler et al., 2003; Gilbertson and Barber, 2003; MacGregor et al., 2006).

It is salutary that, despite their complex emotional needs (Cousins et al., 2010), looked-after young people show lower rates of engagement with services than their peers in the community (Coman and Devaney, 2011). Beck (2006) has indicated this may be due to lack of motivation; feeling that support is not required; believing that problems are located in relationships with others or that someone else is to blame; and having a stigmatised view of mental health services. External inhibitors have been related to the lack of placement stability, a parental advocate and fit within a medical model of service delivery which sometimes fails to comprehend the complexities of needs (Golding, 2010). Co-ordination and meaningful communication between professionals, agencies and foster carers is required to create, what Simmonds (2010:610) describes as 'a therapeutic community' around a young person.

\section{Factors related to the foster carers}

From an ecological perspective, the care environment for looked-after young people is 'highly complex' (Coman and Devaney, 2011:41) with the state's corporate parenting role 
delivered in a context defined by policy and procedure, and different roles taken forward by parents, foster carers, social workers and other professionals. The interaction of these factors can serve to mediate or catalyse the risk of placement breakdown (Oosterman et al., 2007). Research has evidenced the complex care needs of looked-after young people often placing high demands on the caregiving response (Sallnas et al., 2004; Leathers, 2006). Highlighting the importance of this relationship, Brown and Bednar (2006:1499) contended that:

'The interaction between foster parent and child characteristics is more predictive of placement outcome that the characteristics of either alone'.

Exploring this interaction, the research has considered the characteristics and external factors which inform a foster carer's ability to perform this parenting role and the impact this has on placement outcomes. Carers themselves identified a concern for young people's welfare, a strong faith, tolerance, open mindedness, empathy and realistic expectations - as qualities that were necessary to promote good outcomes. These results emanated from Buehler et al.'s (2003) study which drew on a random sample of 22 carers in Knox County, USA. Although this small sample size limited the possibility of a valid generalisation, it generated valuable learning related to the importance of understanding a carer's motivation. Importantly, such motivation might sustain a carer's ability to cope with the significant demands of her role.

The relationship between placement processes and outcomes was highlighted by Khoo and Skoog's (2013) investigation of Swedish foster carers' understanding of placement breakdown. They appropriated an interpretative phenomenological approach to undergird semi-structured interviews with a purposive sample of 8 foster carers from 7 municipalities. The findings suggested that 'breakdown was a complex process rather than a single event' shaped by the interaction of individuals and their context (p. 1). Even though many families were highly motivated to offer the required care, they felt overwhelmed by hastily made placements, with limited information received about the young people entering their homes. Moreover, foster carers struggled to respond appropriately to behavioural issues, particularly adolescent risk taking behaviours, and experienced difficulty establishing contact with social workers. As a cohort, they generally sought greater support from social services in preparation for and during placement. Strikingly, most felt breakdown could have 
been avoided in some cases had there been the requisite support. Although valuable in understanding the foster carer's lived experience from an idiographic perspective, the study was limited by its small sample, the potential for bias in purposive sampling, and gaps in information regarding inclusion criteria, method and data analysis.

In a complementary vein, Leathers' American study (2006) tracked placement outcomes for 179 randomly selected 12-13 year olds, in non-kin foster care, for a five year period following initial telephone interviews with foster carers and social workers. The aim was to examine the risk of placement breakdown among young people placed in foster care for a year or longer. Behaviour problems were identified as a key factor in disruption. However, the young person's integration into the foster family acted as a mitigating factor against breakdown, even when he or she was demonstrating difficult behaviour. For these families in the study, the possibility of the young person leaving the home was a source of distress. Therefore, the results indicated that, where the young person was considered, and felt part of the family, foster carers were more committed to retaining him in the home. This sense of 'felt belonging' may have influenced the way they viewed and understood the young person's behaviours.

Apart from behaviours (such as fire-setting) posing an overriding safety concern (Gilbertson and Barber, 2003), Farmer et al. (2005) asserted that emotional and behavioural difficulties did not, per se, significantly influence a family's ability to sustain a placement. Rather, difficulties emanated from the cumulative impact of these behaviours and the impact of certain types of behaviours related to alcohol or drug misuse, depression and problems with concentration or distractibility. Notably, the high prevalence of mental health disorder among looked-after young people (Stanley et al., 2005; Scott and Hill, 2006) and the possible exacerbation of these conditions during the adolescent stage of development, were common risk factors. In addition, if earmarked foster carers experienced personal strain in the six months prior to the commencement of the placement, it could constrain their ability to sensitively meet the needs of young people after they joined the foster family. Therefore, for Farmer, this finding underlined the importance of pre-placement preparation and induction with designated foster carers to address any antecedent events that might impact on the placement. 


\section{Role of the birth family and contact}

In many countries, the maintenance of family relationships, except when it is contrary to the young person's best interests, is afforded special protection in legislative and policy instruments, predicated on the view that family contact is beneficial for their identityformation. However, for looked-after young people who have often experienced trauma, abuse and neglect within the family context, contact can be a complex and fraught issue (Thomas, 2005).

Reporting on the quality of family contact, and its impact on 86 young people and their placements, Moyers et al. (2006) found that the cohort primarily had contact with their mothers, although some had contact with their fathers and extended family members. Almost half of foster carers expressed difficulties with these arrangements because contact was either unreliable, or there were inappropriate levels of contact. In addition, there were concerns related to safety during contact, the replay of negative relationships, or that contact diminished the foster carers' influence. Importantly, contact mostly improved when it was supervised and social workers engaged with the presenting challenges.

Whilst an attachment perspective considers parental contact as a potential vehicle for promoting good mental health, and the resolution of loss and trauma (Neil and Howe, 2004), for some young people in Moyers et al.'s study, contact continued to be a rejecting, unreliable and neglectful experience. In contradistinction, contact with grandparents was associated with greater stability and more positive placement outcomes. Overall, though, the study showed that difficult experiences of family contact were more likely to result in placement breakdown. However, Moyers et al. (2006) assertion that contact problems significantly affected placement outcomes requires further analysis. Importantly, young people with poor contact experiences were also those who had experienced the highest number of past adversities and were more likely to have been on the Child Protection Register. Acknowledging such contextual factors promotes a more nuanced understanding of placement breakdown.

Adding to this debate, Sinclair et al. (2005) did not find a straightforward connection between family contact and placement outcomes. They postulated that there was a more complex relationship between these variables based on the extent of the young person's 
unresolved need for her birth family, commitment to the placement, and ability to form an attachment with the foster carer. Reinforcing this observation from a systemic perspective, Coman and Devaney (2011) asserted that the birth family could enable or constrain a young person's integration into a foster family, thus influencing placement stability. Pertinent factors here were dynamics within the birth family; young people experiencing anxiety regarding their parents' welfare; and young people's previous experience of poor parenting and how it affected their ability to form new relationships.

In a different study, Murray et al. (2011) found that a number of factors increased foster carers' stress levels, namely: (i) dealing with the escalation of difficult behaviours following contact visits; (ii) young people experiencing abuse during contact; and (iii) young people not wishing to attend visits or being disappointed when their parents did not attend. Yet, Oosterman et al. (2007) did not find contact to be a statistically significant factor leading to placement breakdown. Indeed, they highlighted how co-operation between birth parents and foster carers could lead to beneficial outcomes. Hence, quality of contact could lessen the risk of breakdown. In this context, Andersson (2005) contended that the secure base provided by a lasting, significant attachment figure (often a foster carer) could enable young people to gain a realistic insight into family relationships. In turn, this could build the young person's self-esteem, helping them manage what Fahlberg (1995: 160) termed 'conflicted loyalties' between birth families and foster carers

\section{The role of social workers}

Farmer et al. (2005) argued that social work support was pivotal in alleviating a foster carer's stress, promoting the foster carer's ability to sensitively meet the complex care needs of looked-after young people, and facilitating the conditions for good placement outcomes. The ability to sustain placements has also been related to the relationships between key stakeholders. Foster carers have cited the value of social work support and understanding of the young person's needs and background (Sinclair et al. 2005). Consistency of relationships was seen as highly important and changes of social worker viewed as a predictor of placement breakdown (Egelund and Vitus, 2009).

A number of studies have argued that foster carers' perceptions of support received from social workers was associated with placement breakdown (Buehler et al., 2003; Gilbertson 
and Barber, 2003; Brown and Bednar, 2006; MacGregor et al., 2006). Most strikingly, Khoo and Skoog (2013) found that foster carers believed placement breakdown could have been avoided in some instances with improved pre-placement information and preparation, enhanced support during the placement, and greater discussion of alternatives at the end of placement. Foster carers complained of the limited accessibility of social work support, and the frustration of not having telephone calls returned (Farmer et al., 2004; Khoo and Skoog, 2013). The need for both consistent contact and immediate intervention at times of crisis was underlined (MacGregor et al., 2006).

Placing significant emphasis on their relationship with social work staff, foster carers sought guidance in their role. They wanted responsive and timely support, to be valued and respected by professionals and to be involved in decision-making processes (Sinclair et al., 2005; Brown and Bednar, 2006; Khoo and Skoog, 2013). However, under the rubric of the paramountcy of the young person's welfare (HMSO, 1995), the social worker could at times have a different perspective on needs which foster carers sometimes viewed as criticism of their performance (Brown and Bednar, 2006).

Foster carers have also attributed deficits in social work support to wider systems' failures pointing to high statutory caseloads and lack of resources (Gilbertson and Barber, 2003). McLaughlin (2012: 104) underlined the strictures placed on social work decision-making:

'Social work decisions may be governed by legal statute, agency imperatives, the politics of interagency relationships, professional experience or managerially led initiatives'.

Consequently effecting improvements in support for young people and their foster carers cannot be achieved by social work staff alone: it demands change at an organisational and policy level.

\section{Discussion}

A central theme in this review has been the complexity of state care as delivered by foster carers, social workers and a range of other professionals, with decision-making guided by a range of policies and procedures. The critical understanding emerging is that placement breakdown is generally not a one-off event but rather a complex process occurring over time. Moreover, it involves the interplay between a range of dynamic risk and protective 
factors, operating in the broader context of the young person's history and life experiences and their care-giving environment. Outcomes therefore emerge from interactive risk processes rather than any single factor alone, reinforcing the importance of nurturing protective factors and seeking to mitigate the effects of risk.

The research identified potential risk factors such as older age upon entry to placement, difficult placement history, and behavioural difficulties. In terms of protective factors, young people's integration into the foster care family, good relationships with the birth family, and demonstration of resilience, have been considered influential. The relationship between the young person and foster carers has been found to be a highly significant determining factor of outcomes.

In addition, this review has alluded to the complexities involved in delivering the corporate parenting role - negotiating the often competing demands of a range of stakeholders within a context defined by legislation and policy. A young person's life experience can be shaped by the dynamic and interactive elements within this system, which in turn can function to mediate or catalyse risk of placement breakdown. Consequently, meeting the needs of young people poses significant challenges for this corporate parenting function given the unique vulnerabilities and caring demands of this group. Their needs were characterised by uncertainty, change and transition. Moreover, they were already vulnerable due to previous life experiences and the impact of the care system itself. This explains why they were at high risk of experiencing emotional and mental health difficulties (Coleman, 1974; Fahlberg, 1995; Meltzer et al, 2003; Wulcyzn et al., 2003; James, 2004; Sinclair et al., 2005; Stanley et al., 2005; Crawford and Walker, 2007).

Given the recurring theme of 'complexity' in all of this, social work practitioners need to embrace strategies for understanding multi-causal factors and multi-dimensional forms of intervention - in order to promote the best interests of the young people. Typically, they must attend to practical affairs and the emotional and behavioural domains of experience. More than that, they are required to embrace administrative and legal mandates. Sociocultural influences are also to the fore. Fundamentally, in order to deal with this level of complexity, the practitioner must draw on different types of explanatory theory. 
Collingwood and Davies' (2008) notion of theory to inform is helpful in this context for practitioners attempting to make sense of complex social situations. Theory to inform is the knowledge gained deductively from the social sciences that explains human behaviour, addresses causation and illuminates the deep-rooted mechanisms underlying human action. Theories to inform that are most relevant to foster care include attachment theory, theories of trauma and resilience, an understanding of the life course (including theories of child and adolescent development) and, lastly, ecological and systems theories. Such theories enable practitioners to move from 'surface' to 'depth', in order to identify the causal mechanisms affecting positive and negative outcomes. We have already alluded to the significance of human attachment, as a concept that is central to foster care. The bond between the young person and his carers, and with his biological parents and kin, has been a prominent theme arising from the review of literature. Practitioners need to find ways of building multiple attachments that enhance inner working models, and to understand the defence mechanisms that are employed when identity, security and stability are threatened.

The review of the literature has also made reference to trauma. Young people often enter the care system having suffered complex trauma, which may be further compounded by experiences within the care system itself, such as placement disruption. It is notable that early, traumatic experiences of child abuse can directly increase the risk of developing a mental health condition, which the literature highlights as a pervasive occurrence. In addition to the spectrum of mental disorder, trauma can lead to memory and concentration problems, emotional numbing and forms of behavioural avoidance. In responding to trauma in young people in foster care, social workers need to appreciate that it affects not only physical and psychological realms of being but also the social domains of relationship and interaction within family and social groups (Joseph and Murphy, 2014). This affirms the centrality of a psychosocial, relational approach when working with carers and young people. Building resilience also involves a psychosocial approach, one attending to psychological constructs such as mastery, competence, self-efficacy and optimism but also building up social connections outside the foster home, enhancing talents and interests and also social capital (Daniel and Wassell, 2002; Ungar, 2004).

The life course, and its psychosocial stages, reminds social workers of the importance of a young person's history as it has unfolded from birth onwards. The significance of various 
transitions prior to entering foster care, as the literature review reveals, have a determinative effect on placements and foster carers should be fully appraised of the young person's unique psycho-biographical experience. At each transition point, there may be psycho-social challenges to face and resolve. What is of concern here is the effect of loss, change, illness, trauma, crisis, estrangement, re-union and opportunities for growth and development. When responding to these events, social workers must concentrate on developing a holding environment for young people and their carers, one where a therapeutic alliance is maintained.

In addition, social workers can make sense of complex needs through an appreciation of the different systems surrounding the young person. Here, systems and ecological theories allow for multifactorial explanations. For instance, Bronfenbrenner's (1979) ecological approach to child development and well-being conceives of four interlacing systems including the 'micro-system' (the domain of intimate personal interaction); the 'mesosystem' (the network of interacting micro-systems); the 'exo-system' (systems outside the family's involvement which indirectly affect it); and the 'macro-system' (the large scale system of political-economy). As the literature review above shows, young people are affected by a range of psycho-social factors within these systems, including contact with their parents, siblings and extended family. Importantly, ecological theory suggest that an intervention in one system, can have impact on others systems. In relation to foster care, building relationships of trust with biological family members might well have a stabilising effect on the placement.

\section{Conclusion}

This article summarises a practitioner-led review of the factors which influence the breakdown of foster care placements for young people. It illustrates a complex picture of dynamic and interlinking risk and protective factors. It shows how they operated in the broader context of the young person's history and life experiences. Apart from the existence of overriding safety concerns, placement breakdown would not appear to be the result of a single factor alone. Whilst the significance or weighting attached to risk factors can vary from case to case, breakdown would appear to result from an interactive process over time. 
These findings underline the importance of the practitioner understanding the process of placement breakdown to aid the effective delivery of support to looked-after young people and their foster carers, with the ultimate aim of promoting placement stability. The needs of looked-after young people are often intense, enduring and complex exerting high demands on foster carers. Recognising potential risk factors at an early stage should enable timely targeting of appropriate interventions, in turn sustaining foster carers' capacity to cope.

Whilst difficult and aggressive behaviours are acknowledged as a risk factor for placement breakdown, the findings have also evidenced the need to view them as a manifestation of emotional and mental health difficulties. Therefore, social workers and professionals from other disciplines, must harness a range of theories to inform a deep understanding of behaviour in order to build a therapeutic community around the young person, sharing understanding of their needs and co-ordinating support.

Significantly, studies within this review have recognised the challenges, from an attachment perspective, that looked-after young people can experience in building relationships with new foster carers. Becoming integrated within a foster care family can be a significant achievement for young people and forms a protective factor against placement breakdown, even when the young person demonstrates difficult behaviour. The secure base provided by a foster care family can offer young people much needed stability and promote positive adjustment in adulthood. 


\section{References}

Andersson, G. (2005). Family relations, adjustment and well-being in longitudinal study of children in care. Child and Family Social Work, 10, 43-56.

Atwool, N. (2006). Attachment and resilience: Implications for children. Care Child Care in Practice, 4, 312-330.

Barth, R., Crea, T., John, K., Thorburn, J. and Quinton, D. (2005). Beyond attachment theory and therapy: Towards sensitive and evidence based intervention with foster and adoptive families in distress. Child and Family Social Work, 10, 257-268.

Beck, A. (2006). User's views of looked-after children's mental health services. Adoption and Fostering, 30, 53-63.

Berridge, D. and Cleaver, H. (1987). Foster home breakdown. Oxford: Blackwell.

Bowlby, J. (1969). Attachment and loss Vol. 1. London: Hogarth Press.

Brown, J. and Bednar, L. (2006). Foster parent perceptions of placement breakdown. Children and Youth Services Review, 28, 1497-1511.

Buehler, C., Cox, M.E. and Cuddeback, G. (2003). Foster parents' perceptions of factors that promote or inhibit successful fostering. Qualitative Social Work, 2, 61-84.

Canavan, J. (2008). Resilience: Cautiously welcoming a contested concept. Child Care in Practice, 14, 1-7.

Cashmore, J. and Paxman, M. (2006). Predicting after-care outcomes: The importance of felt security. Child and Family Social Work, 11, 232-241.

Coleman, J. (1974). Relationships in adolescence. London: Routledge

Collingwood, P. and Davies, M. (2008). Introduction: Knowledge, theory and social work practice - An Easy Access Approach, in M. Davies (ed.) The Blackwell companion to social work (pgs. 1-8). London: Blackwell.

Coman, W. and Devaney, J. (2011). Reflecting on outcomes for looked-after children: An ecological perspective. Child Care in Practice, 17, 37-53. 
Cousins, W., Taggart, L., and Milner, S. (2010). Looked after or overlooked? An exploratory investigation of the mental health issues of adolescents living in state care in Northern Ireland. Psychology, Health and Medicine, 15, 497-506.

Crawford, K. and Walker, J. (2007). Social Work and Human Development. Exeter: Learning Matters Ltd.

Daniel, B. and Wassell, S. (2002). Adolescence: Assessing and promoting resilience in vulnerable children. London: Jessica Kingsley Publishers.

DHSSPSNI (2005). Area Child Protection Committee Regional Policy and Procedures, http://www.dhsspsni.gov.uk/acpcregionalstrategy.pdf, accessed $16^{\text {th }}$ August 2013.

DHSSPS (2012). Improving and safeguarding social wellbeing: A strategy for social work 2012-2022. Belfast: DHSSPS.

Egelund, T. and Vitus, K. (2009). Breakdown of care: the case of Danish teenage placements. International Journal of Social Welfare, 18, 45-56.

Fahlberg, V. (1995). A child's journey through placement. London: British Association for Adoption and Fostering.

Farmer, E., Lipscombe, J. and Moyers, S. (2004). Fostering adolescents. London: Jessica Kingsley Publishers.

Farmer, E., Lipscombe, J. and Moyers, S. (2005). Foster carer strain and its impact on parenting and placement outcomes for adolescents. British Journal of Social Work, 35, 237253.

Fernandez, E. (2008). Unravelling emotional, behavioural and educational outcomes in a longitudinal study of children in foster care. British Journal of Social Work, 38, 1283-1301.

Gilligan, R. (2008). Promoting resilience in young people in long-term care - the relevance of roles and relationships in the domains of recreation and work. Journal of Social Work Practice, 22, 37-50.

Gilbertson, R. and Barber, J. (2003). Breakdown of foster care placement: Carers' perspectives and system factors. Australian Social Work, 56, 329-339. 
Golding, K. (2010). Multi-agency and specialist working to meet the mental health needs of children in care. Clinical Child Psychology and Psychiatry, 15, 573-587.

Hek, R., Aiers, A., Hughes, N. and Morris, K. (2010). Promoting best outcomes and providing best support for carers. International Centre for Research and Innovation in Fostering. http://www.nottingham.ac.uk/children-and-childhood-network/documents/promotingbest-outcomes-for-children-and-providing-best-support-for-carers.pdf, accessed $20^{\text {th }}$ April 2013.

HMSO (1995). The Children (Northern Ireland) Order 1995. Belfast: HMSO.

James, S. (2004). Why do foster care placements disrupt? An investigation of reasons for placement change in foster care. Social Service Review, 78, 601-627.

Jones Harden, B. (2004). Safety and stability for foster children: A developmental perspective. The Future of Children, 14, 30-47.

Joseph, S. and Murphy, D. (2014). Trauma: A unifying concept for social work. British Journal of Social Work, 44, 1094-1109.

Khoo, E. and Skoog, V. (2013). The road to placement breakdown: Foster parents' experiences of the events surrounding the unexpected ending of a child's placement in their care. Qualitative Social Work, 6, 1-15.

Leathers, S. (2006). Placement disruption and negative placement outcomes among adolescents in foster care: The role of behaviour problems. Child Abuse and Neglect, 30, 307-324.

Leve, L.D., Harold, G.T., Chamberlain, P., Landsverk, J.A., Fisher, P.A. and Vostanis, P. (2012). Practitioner review: Children in foster care - vulnerabilities and evidence-based interventions that promote resilience processes. Journal of Child Psychology and Psychiatry, $53,1197-1211$. 
MacGregor, T., Rodger, S., Cummings, A. and Leschied, A. (2006). The needs of foster parents: A qualitative study of motivation, support and retention. Qualitative Social Work, 5, 351-368.

McLaughlin, H. (2012). Understanding social work research ( $2^{\text {nd }}$ ed.). London: Sage.

Meltzer, H., Gatward, R., Corbin, T., Goodman, R. and Ford, T. (2003). The mental health of young people looked-after by Local Authorities in England. London: The Stationery Office.

Moyers, S., Farmer, E. and Lipscombe, J. (2006). Contact with family members and its impact on adolescents and their foster placements. British Journal of Social Work, 36, 541599.

Murray, L., Tarren-Sweeney, M. and France, K. (2011). Foster carer perceptions of support and training in the context of high burden of care. Child and Family Social Work, 149-158.

Neil, E. and Howe, D. (2004). Contact in adoption and permanent foster care: Research, theory and practice. London: British Association for Adoption and Fostering.

Newman, T., Moseley, A., Tierney, S. and Ellis, A., (2005). Evidence-based social work: A guide for the perplexed. Dorset: Russell House Publishing.

Oosterman, M., Shuengel, C., Wim Slot, N., Bullens, R. and Doreleijers, T. (2007). Disruptions in foster care: A review and meta-analysis. Children and Youth Services Review, 29, 53-76.

Pawson, R., Boaz., A., Grayson, L., Long, A. and Barnes, C. (2003). Knowledge review: 3 types and quality of knowledge in social care. London: Social Care Institute for Excellence.

Sallnas, M., Vinnerlijung, B. and Kyhle Westermark, P. (2004). Breakdown of teenage placements in Swedish foster and resident care. Child and Family Social Work, 9, 141-152.

Schofield, G. and Beek, M. (2009). Growing up in foster care: providing a secure base through adolescence. Child and Family Social Work, 14, 255-266.

Scott, J. and Hill, M. (2006). The health of looked-after and accommodated young people in Scotland: Messages from research. Edinburgh: Social Work Inspection Agency. 
Simmonds, J. (2010). The making and breaking of relationships: Organisational and clinical questions in providing services for looked-after children. Clinical Child Psychology and Psychiatry, 15, 601-612.

Sinclair, I., Wilson, K. and Gibbs, I. (2005). Foster placements: Why they succeed and why they fail. London: Jessica Kingsley.

Stanley, N., Riordan, D. and Alaszewski, H. (2005). The mental health of looked-after children: Matching response to need. Health and Social Care in the Community, 13, 239-248.

Stein, M. (2008). Resilience and young people leaving care. Child Care in Practice, 14, 35-44.

Thomas, N. (2005). Social work with young people in care: Looking after children in theory and practice. Hampshire: Palgrave Macmillan.

Ungar, M. (2004). Nurturing hidden resilience in troubled youth. Toronto: University of Toronto.

Western Health and Social Care Trust (2012). Fostering Services. http://www.westerntrust.hscni.net/1739.htm, accessed $1^{\text {st }}$ January 2013.

Wulczyn, F., Kogan, J. and Jones Harden, B. (2003). Placement stability and movement trajectories. Social Services Review, 77, 212-236. 